\title{
Environmental Cadmium Enhances Lung Injury by Respiratory Syncytial Virus Infection
}

Xin Hu, ${ }^{*}$ Ki-hye Kim, ${ }^{\dagger}$ Youri Lee, ${ }^{\dagger}$ Jolyn Fernandes, ${ }^{*}$ M. Ryan Smith, ${ }^{*}$ Yu-Jin Jung, ${ }^{\dagger}$ Michael Orr, ${ }^{*}$ Sang-Moo Kang, Dean P. Jones, ${ }^{*}$ and Young-Mi Go*

From the Division of Pulmonary Medicine, ${ }^{*}$ Department of Medicine, Emory University, Atlanta; and the Institute for Biomedical Sciences, ${ }^{\dagger}$ Georgia State University, Atlanta, Georgia

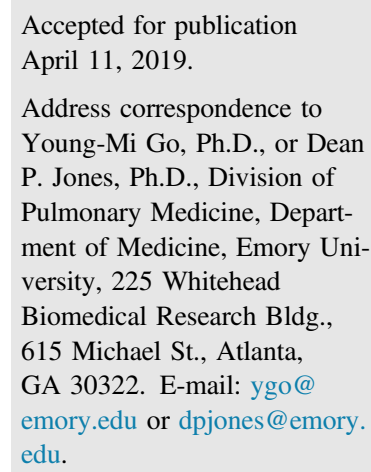

\begin{abstract}
Cadmium (Cd) is a naturally occurring environmental toxicant that disrupts mitochondrial function at occupational exposure levels. The impacts of $\mathrm{Cd}$ exposure at low levels through dietary intake remain largely uncharacterized. Human respiratory syncytial virus (RSV) causes severe morbidity, which can require hospitalization and result in death in young children and elderly populations. The impacts of environmental Cd exposure on the severity of RSV disease are unknown. Herein, we used a mouse model to examine whether $\mathrm{Cd}$ pre-exposure at a level of dietary intake potentiates pulmonary inflammation on subsequent infection with RSV. Mice were given Cd or saline in drinking water for 28 days. Subsets of these mice were infected with RSV at 5 days before the end of the study. Cd pre-exposure caused relatively subtle changes in lung; however, it elevated the IL-4 level and altered metabolites associated with fatty acid metabolism. After RSV infection, mice pre-exposed to Cd had elevated lung RSV titer and increased inflammation, as measured by histopathology, immune cell infiltration, cytokines, and chemokines. RSV infection after Cd pre-exposure also caused widespread perturbation in metabolism of glycerophospholipids and amino acids (Trp, Met, and Cys, branched-chain amino acids), as well as carnitine shuttle associated with mitochondrial energy metabolism. The results show that $\mathrm{Cd}$ burden by dietary intake potentiates RSV infection and severe disease with associated mitochondrial metabolic disruption. (Am J Pathol 2019, 189: 1513-1525; https://doi.org/10.1016/j.ajpath.2019.04.013)
\end{abstract}

Respiratory syncytial virus (RSV) infection causes serious pulmonary disease and death in high-risk infants and adults, resulting in $>100,000$ bronchiolitis and pneumonia hospitalizations annually in the United States. ${ }^{1-3}$ RSV is a significant global health care burden, causing three to four million yearly hospitalizations worldwide and 66,000 to 199,000 RSV-associated deaths. ${ }^{4}$ Also, severe RSV infection early in childhood is associated with developing asthma disease later in life. ${ }^{5}$ Recently, severe RSV disease in adults was shown to be associated with $\mathrm{T}$-cell responses during infection. ${ }^{6}$ Risk factors for more severe RSV illness in adults include pulmonary and cardiopulmonary conditions, prematurity and early age of infection, immunosuppression, congenital heart disease, and neurologic injury. ${ }^{1,7}$ In addition, cigarette smoke and air pollution increase incidence of severe lower respiratory tract disease. ${ }^{8}$ However, impacts of other environmental pollutants, such as heavy metal exposure, on the risk of severe illness caused by RSV infection remain unknown.

Cadmium $(\mathrm{Cd})$ is a naturally occurring toxic element. Extensive data establish that $\mathrm{Cd}$ exposure from cigarette smoking and occupational sources causes acute and chronic lung toxicities. ${ }^{9}$ Less is known about the impact of low-level chronic $\mathrm{Cd}$ exposure in nonsmokers, mostly obtained from dietary intake. Lower exposure of $\mathrm{Cd}$ in the general population is usually assessed by urinary concentration of $\mathrm{Cd}$; thus, little information is provided on local accumulation of

Supported by National Institute of Environmental Health Sciences grants R01 ES023485 (D.P.J. and Y.-M.G.) and R21 ES025632 (D.P.J. and Y.M.G.); NIH grant S10 OD018006 (D.P.J.); and NIH/National Institute of Allergy and Infectious Diseases grants R01 AI105170 (S.-M.K.), R01 AI093772 (S.-M.K.), and R21 AI119366 (S.-M.K.).

X.H., K.-h.K., Y.L., J.F., and M.R.S. contributed equally to this work. Disclosures: None declared. 
$\mathrm{Cd}$ in the lungs. In one study, a significantly higher $\mathrm{Cd}$ level in a lung sample was found in chronic obstructive pulmonary disease patients versus control smokers. ${ }^{10}$ Therefore, cadmium has been suggested as a neglected link to lung disease and there is a need for new studies on local cadmium levels and their relation to lung pathology. ${ }^{11}$ Humans have no effective mechanisms for $\mathrm{Cd}$ elimination, ${ }^{12,13}$ and $\mathrm{Cd}$ concentrations in human organs progressively increase with age. ${ }^{14}$ Previous studies showed that age is an important sensitizing factor in toxicity of heavy metals, including Cd. ${ }^{15,16}$

Our previous studies in human cells and mouse models showed that low-level $\mathrm{Cd}$ exposure stimulates proinflammatory signaling responses, including oxidation of thiol/disulfide oxidation-reduction systems, disruption of the actin-cytoskeleton regulation, nuclear translocation of thioredoxin-1, and increased NF- $\kappa \mathrm{B}$ activity and proinflammatory cytokines. ${ }^{17,18}$ In addition, studies with a thioredoxin-1 transgenic mouse overexpressing thioredoxin1 in nuclei showed that increased thioredoxin- 1 abundance in nuclei potentiated inflammation associated with cardiovascular disease. ${ }^{19}$ Recently, we found that mice with lung $\mathrm{Cd}$ burden of nonsmoking humans had exacerbated lung inflammation caused by influenza virus infection. ${ }^{20}$ In this and other studies of virus and bacterial infection, smoking, and $\mathrm{Cd}$ burden, we found that high-resolution metabolomics (HRM) provided a useful metabolic phenotyping to complement inflammatory markers. ${ }^{20-24}$

In the present study, we used $\mathrm{Cd}$ pre-exposure in mice to generate lung $\mathrm{Cd}$ burden at a level of dietary intake in humans to test for potentiated pulmonary inflammation and injury on subsequent infection with RSV. We measured metabolites and metabolic pathways using advanced HRM, and conventional histopathology and inflammation markers of lung tissues and extract after pre-exposure of $\mathrm{Cd}$ and then RSV infection. Both HRM and inflammation markers showed that low-dose $\mathrm{Cd}$ pre-exposure exacerbated RSV infection-induced pulmonary histopathology and inflammation.

\section{Materials and Methods}

\section{Animals, Cd Exposure, and RSV Infection}

Experimental protocols for animal studies were approved by Emory University (Atlanta, GA) and Georgia State University (Atlanta, GA) Institutional Animal Care and Use Committees, and experiments were performed in accordance with the relevant guidelines and regulations. Eight-week-old C57BL6 mice $[n=8$ per group, 4 groups (control, Cd, RSV, Cd + RSV)], purchased from Jackson Laboratory (Bar Harbor, ME), were housed in clean facilities and fed standard mouse diet (Laboratory Rodent Diet 5001; LabDiet, St. Louis, MO). Sample size ( $n=8$ per group) was determined statistically before experimentation and also considering total amount of tissues required for all assays performed in this study. Mice were given sterile-filtered drinking water without or with $3.3 \mathrm{mg} / \mathrm{L} \mathrm{CdCl}{ }_{2}$ (SigmaAldrich, St. Louis, MO) for 4 weeks. Cd content in standard mouse diet $\left(62 \pm 1 \mathrm{ng} / \mathrm{g}\right.$ food) was negligible ${ }^{25}$ compared with $3.3 \mathrm{mg} / \mathrm{L} \mathrm{Cd}$ in drinking water. After $\mathrm{Cd}$ exposure for 23 days, mice were intranasally challenged with RSV A2 strain $\left(1 \times 10^{6}\right.$ plaque-forming units $) 5$ days before completing 4-week $\mathrm{Cd}$ exposure. Changes in body weight, enhanced airway pause, and lung virus titers were determined, as described previously, ${ }^{26,27}$ to monitor severity of illness and lung function associated with Cd toxicity and/or infection (Supplemental Figure S1).

\section{Quantification of $\mathrm{Cd}$ and 10 Other Metals in Lung by Inductively Coupled Plasma Mass Spectrometry}

Lung tissue ${ }^{114} \mathrm{Cd},{ }^{55} \mathrm{Mn},{ }^{64} \mathrm{Zn},{ }^{77} \mathrm{Se},{ }^{24} \mathrm{Mg},{ }^{27} \mathrm{Al},{ }^{51} \mathrm{~V},{ }^{52} \mathrm{Cr}$, ${ }^{58} \mathrm{Ni},{ }^{98} \mathrm{Mo}$, and ${ }^{134} \mathrm{Ba}$ were quantified and normalized to tissue mass, as previously described. ${ }^{25}$ Briefly, $50 \mathrm{mg}$ of the lung tissue was subjected to wet acid digestion using nitric acid and hydrogen peroxide. Each sample was diluted to 10 $\mathrm{mL}$ and run in triplicate using inductively coupled plasma mass spectrometry (iCAP Q ICP-MS; Thermo Fisher Scientific, Waltham, MA), in collision cell mode using kinetic energy discrimination. For each metal, a linear standard curve was established on a range of 0.25 to 60 parts per billion in the same run as samples.

\section{Histopathology}

Intact lungs from all mice in each group were harvested at the time of completing $\mathrm{Cd}$ exposure for 4 weeks and day 5 after RSV infection. For histology, left lung tissues were fixed with $10 \%$ normal-buffered formalin in phosphatebuffered saline, as described previously. ${ }^{26,27}$ At least eight sections of lung tissues were stained with hematoxylin and eosin to evaluate lung inflammation, Periodic acid-Schiff (PAS) stain for mucus production, and hematoxylin and Congo red for eosinophilic infiltration. Images were acquired using an Axiovert 100 (Zeiss, Oberkochen, Germany) at $\times 100$ magnification; and inflammation was blindly scored by three lung histology experts in the airway bronchioles, vessels, and interstitial spaces in a range of 0 (no inflammation) to 10 (severe inflammation).

\section{Immune Cells and Cytokine and Chemokine Measurements}

Lung tissue lysates and bronchoalveolar lavage (BAL) fluids were used to analyze immune cells and cytokines in lung and respiratory tracts. Single-cell suspensions from the lung tissues (homogenized and passed through a strainer) and BAL fluids were stained with fluorescence-labeled anti-mouse lymphocytes and CD4 and CD8 antibodies (Biolegend, San Diego, CA) and quantified by fluorescence-activated cell sorting, as previously described. ${ }^{28}$ Data acquired using an 
LSR-II/Fortessa (Becton-Dickinson, Franklin Lakes, NJ) were analyzed by FlowJo version 9/X (Tree Star, Inc., Ashland, OR). Monocytes $\left(\mathrm{CD} 11 \mathrm{~b}^{+} \mathrm{CD} 11 \mathrm{c}^{-} \mathrm{Ly} 6 \mathrm{c}^{\mathrm{hi}} \mathrm{F} 4 / 80^{+}\right)$ were gated on $\mathrm{Ly} 6 \mathrm{c}^{\mathrm{hi}} \mathrm{F} 4 / 80^{+}$cells from the pregated $\mathrm{CD}_{11 \mathrm{~b}^{+}} \mathrm{CD} 11 \mathrm{c}^{-}$cells. The number of monocytes was calculated by multiplying the number of lung and BAL fluid cells in each mouse with the gated cell proportions. The levels of cytokines in lung were determined in lung tissue extracts without perfusion that were homogenized and passed through a strainer. Interferon (IFN)- $\gamma$, IL-1 $\beta$, IL-6, and IL-4 for cytokines, regulated on activation, normal $\mathrm{T}$ cells expressed and secreted (RANTES), and keratinocyte cytokine $(\mathrm{KC})$ for chemokines were measured in BAL fluid and lung lysates by corresponding cytokine enzyme-linked immunosorbent assay using Ready-Set-Go kits, following the manufacturer's procedures (eBioscience, San Diego, CA).

\section{HRM}

Lung tissues (20 to $30 \mathrm{mg}$ ) and BAL fluid $(50 \mu \mathrm{L})$ were used to extract metabolites in acetonitrile/water (2:1) containing internal standards, ${ }^{29}$ following the procedures as described previously. ${ }^{21,25,30}$ Each sample was analyzed with LTQ-Velos Orbitrap mass spectrometer (85 to 2000 mass/ charge; Thermo Fisher Scientific); each analysis was performed with three technical replicates. Chromatographic separation was achieved with Accucore hydrophilic interaction liquid chromatography (HILIC; $100 \times 2.1-\mathrm{mm}$, 2.6- $\mu \mathrm{m}, 80-\AA$ ) chromatography (Thermo Fisher Scientific) under positive ion mode. Mass spectral data were extracted with apLCMS ${ }^{31}$ and xMSanalyzer ${ }^{32}$ recovering metabolic features with high-resolution mass/charge paired with retention time. Data were prefiltered to retain only features with nonzero values in $>80 \%$ in all samples, and data from triplicate analyses were averaged before statistical and bioinformatic analyses.

\section{Metabolomics Data Analysis and Integrative Functional Network Analysis}

Analysis of variance and limma test were used to select features that differed between groups. Significant features (raw $P<0.05$ ) were further studied by pathway enrichment analyses using Mummichog version 1.0.10. ${ }^{33}$ This approach protects against type 2 statistical error by including all features at $P<0.05$ and protects against type 1 statistical error by permutation testing in pathway enrichment analysis. $^{34}$ Hierarchical clustering analysis and principal component analysis were used for untargeted comparison of the significant features differentiating treatment groups (raw $P<0.05$ by limma test). Lung inflammatory marker measurements and metabolome data were integrated using a data-driven integration and differential network analysis tool, xMWAS software version $0.552 .{ }^{35}$ Partial leastsquares regression, a variable selection and dimensionality reduction method, was used to conduct pairwise correlation analysis among metabolome $(8$ samples $\times 11,341$ metabolic features), 9 inflammatory markers $\left(\mathrm{CD}^{+}{ }^{+} \mathrm{T}\right.$ cells, $\mathrm{CD} 8^{+} \mathrm{T}$ cells, monocytes, KC, RANTES, IFN- $\gamma$, IL-1, IL-6, and IL4), and 11 metals $\left({ }^{114} \mathrm{Cd},{ }^{55} \mathrm{Mn},{ }^{64} \mathrm{Zn},{ }^{77} \mathrm{Se},{ }^{24} \mathrm{Mg},{ }^{27} \mathrm{Al},{ }^{51} \mathrm{~V}\right.$, ${ }^{52} \mathrm{Cr},{ }^{58} \mathrm{Ni},{ }^{98} \mathrm{Mo}$, and ${ }^{134} \mathrm{Ba}$ ). Selected metabolic features were used for metabolic pathway enrichment analysis using Mummichog $^{33}$ and annotation obtained with xMSannotator $^{36}$ version 1.3.2 with Human Metabolome Database version 3.5 (http://www.hmdb.ca/downloads), ${ }^{37}$ which provides level 3 determination of tentative identity, according to the Metabolomics Standards Initiative. ${ }^{38}$

\section{Statistical Analysis}

Quantification data were analyzed using Prism 5 software (GraphPad Software, Inc., La Jolla, CA), and results are presented as means \pm SEM. Statistical analysis was performed by unpaired two-tailed $t$-test. $P<0.05$ was considered statistically significant. Limma $t$-test and $t$-test (two-tailed with Welch's correction for unequal variance) were used to test significance. The significance level was $P<0.05$ for all univariate tests; Benjamini and Hochberg false discovery rate was used for multiple comparisons. ${ }^{39}$

\section{Additional Metabolomics Data}

Metabolomics data have been provided in Supplemental Tables with the article: significant metabolites from lung and BAL fluid mapped to metabolic pathways (Supplemental Table S1), annotation and pathway analysis of metabolites in inflammation $\times$ metabolite interaction network (Supplemental Table S2), and in inflammation $\times$ metabolite $\times$ metal interaction network (Supplemental Table S3).

\section{Results}

Low-Dose Cd Pre-Exposure Leads to Increased Lung RSV Viral Loads and Exacerbates Lung Inflammation after RSV Infection

Mice were weighed every 7 days during $\mathrm{Cd}$ intake, and then daily for 5 days during RSV infection until termination. Lung Cd content was substantially higher in mice given $\mathrm{Cd}$ ( $3.0 \pm 0.3 \mathrm{ng} / \mathrm{g}$ tissue; $n=16)$ compared with the control group ( $0.1 \mathrm{ng} / \mathrm{g}$ tissue; $n=15$ ) (Supplemental Figure S1A), but within a range found in lungs of nonsmoking humans. ${ }^{40-42}$ This low Cd burden did not have an effect on mouse body weight changes [control, $25.2 \pm 0.4 \mathrm{~g}$; Cd, $25.0 \pm 0.3 \mathrm{~g}$ (at day 0); control, $27.9 \pm 0.4 \mathrm{~g}$; Cd, $28.1 \pm 0.3 \mathrm{~g}$ (at day 25); $n=16$ for each group]. After RSV infection, mice lost $8 \%$ to $10 \%$ of their body weight at 2 days and then recovered weight back to that of the group without infection (Supplemental Figure S1B). Both RSVinfected mice with and without $\mathrm{Cd}$ intake showed elevated airway hyperreactivity, measured by enhanced airway pause 
with methacholine challenge $(100 \mathrm{mg} / \mathrm{mL})$, but there was no difference in enhanced airway pause values between the two groups (Supplemental Figure S1C). Lung virus titers were significantly higher in the Cd + RSV group compared with those in the RSV only group (Figure 1D), suggesting that low-dose Cd burden adversely impacted the balance of RSV production and clearance in the lungs.

Because RSV infection causes bronchiolitis and pneumonia, the impact of $\mathrm{Cd}$ pre-exposure on lung pathophysiology was determined after RSV infection by comparing histology in the 4 groups (control, Cd, RSV, and Cd + $\mathrm{RSV} ; n=8$ per group) (Figure 1). Representative images for each group are shown for lung sections stained with the following: hematoxylin and eosin for inflammatory cellular infiltration (Figure 1A), PAS for mucus production (Figure 1B), and hematoxylin and Congo red for eosinophilic infiltration (Figure 1C). Infiltration-positive area on the respective staining was quantified, as shown in Figure 1 [inflammation score (Figure 1E), \% PAS positive (Figure 1F), and eosinophils (Figure 1G)]. Cd pre-exposure exhibited pulmonary inflammation, even in the absence of viral infection, as evidenced by moderate but significant effects on increasing the airways and overall inflammatory histopathology in the Cd group compared with the vehicle control group. Nonetheless, the effects of $\mathrm{Cd}$ exposure on mucus production and eosinophilic infiltration were minimum. RSV infection resulted in moderate increases in inflammation and cellular infiltrates (hematoxylin and eosin staining), mucus production, and eosinophilic infiltration. Cd pre-exposure, followed by RSV infection (Cd $+\mathrm{RSV})$, displayed the most severe pulmonary histopathology, as evidenced by all of the staining parameters (hematoxylin and eosin, PAS, and hematoxylin and Congo red). Quantification results of inflammation scores were as follows:
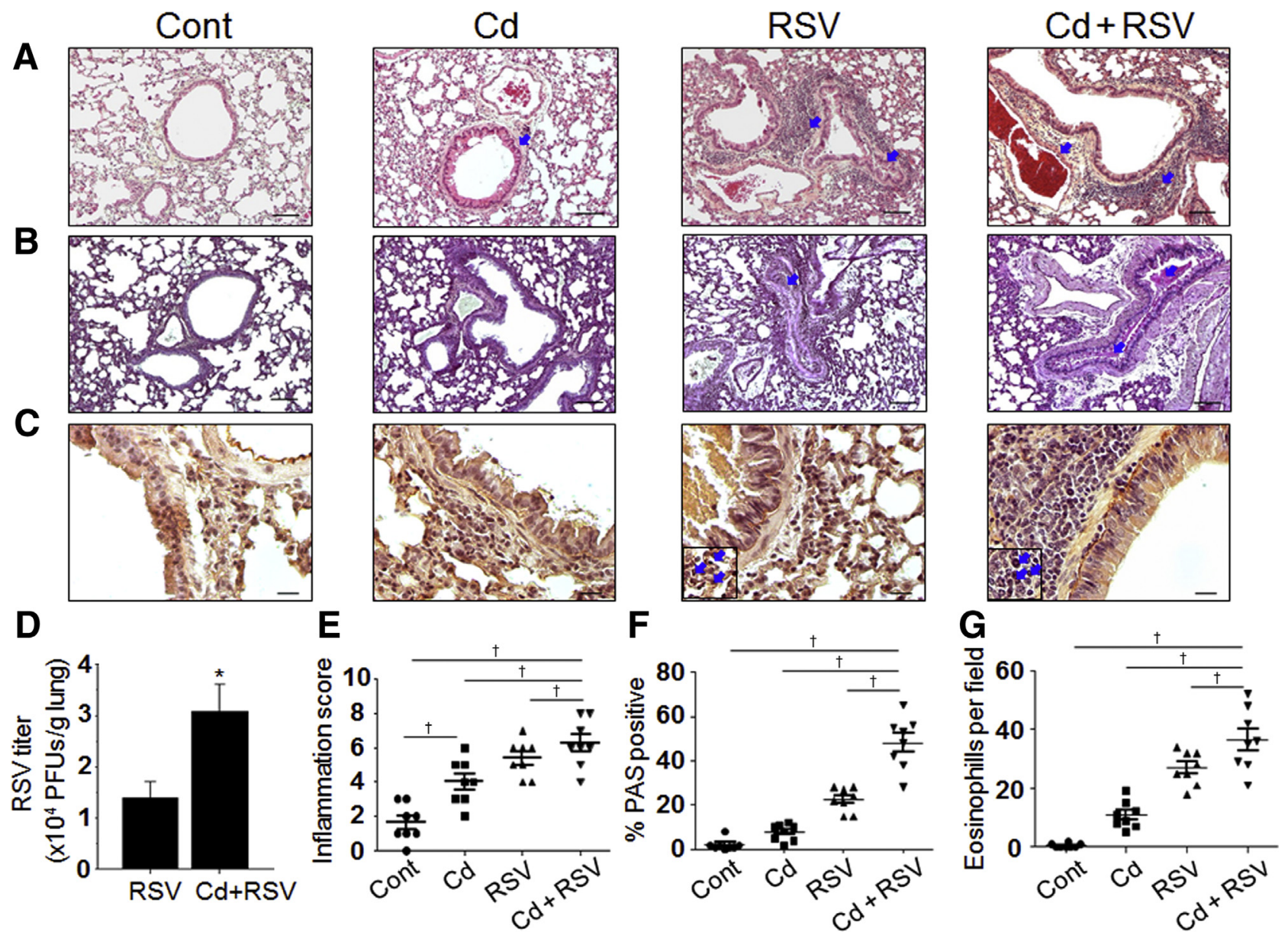

Figure 1 Low-level cadmium (Cd) burden elevated lung histopathology and viral titers after respiratory syncytial virus (RSV) challenge. A-C: Collected lung tissues from individual mouse from all four groups [vehicle control (Cont), Cd only, RSV, and Cd + RSV] at day 5 after RSV challenge (28 days of Cd administration) were examined for histopathology after staining with hematoxylin and eosin (A), periodic acid-Schiff (PAS; B), and hematoxylin and Congo red (H\&CR; C). Insets: Magnified eosinophilic cell spots positively stained with H\&CR. Arrowheads indicate inflamed airways, blood vessel, and eosinophil granulocytes. D: RSV lung viral titers at day 5 after infection. E-G: Images taken by microscopy were used for quantification, as follows: inflammation score using a 1 to 10 scoring system, where 1 indicates minimal pathology and 10 indicates maximum pathology for the airways, interstitial spaces, and blood vessels (E); \% of PAS-positive airway mucus expression (F); and H\&CR-positive eosinophil cells counted under the microscopic field (G). Statistical significances were performed by one-way analysis of variance. Data are expressed as means \pm SEM. $n=8$ for all groups $(\mathbf{D}-\mathbf{G}) .{ }^{*} P<0.05$ versus RSV only; ${ }^{\dagger} P<$ 0.05. Scale bars $=100 \mu \mathrm{m}(\mathbf{A}-\mathbf{C})$. Original magnification, $\times 100(\mathbf{A}-\mathbf{C})$. PFU, plaque-forming unit. 
RSV, $4.4 \pm 0.5$; Cd + RSV, $6.6 \pm 0.5(P<0.05)$. Quantification results of $\%$ PAS-positive cells were as follows: RSV, $22 \% \pm 5 \%$; $\mathrm{Cd}+\mathrm{RSV}, 50 \% \pm 5 \%(P<0.001)$ Quantification results of eosinophils per field were as follows: RSV, $23 \pm 7$; Cd + RSV, $43 \pm 7(P<0.05)$. Cumulatively, the results show that pre-exposure to lowlevel $\mathrm{Cd}$ burden potentiates lung histopathology due to RSV infection in mice.

\section{Cd Pre-Exposure Promotes Monocyte and Lymphocyte Infiltration, and Chemokine and Cytokine Production, in the Lungs on RSV Infection}

The impact of $\mathrm{Cd}$ pre-exposure was further examined by measuring effects on monocytes and lymphocyte infiltrates in the lung (Figure 2, A-C) and airway (BAL fluid) (Figure 2, D-F) samples after RSV infection. The Cdexposed mice without RSV infection showed little to no increase in monocytes in either lung or BAL fluid samples. $\mathrm{Cd}$ alone resulted in moderate levels of lymphocytes, including $\mathrm{CD}^{+}$and $\mathrm{CD}^{+}{ }^{+} \mathrm{T}$ cells in the lungs but not in BAL fluid samples compared with the control mice. With RSV infection, monocytes and $\mathrm{CD}^{+}{ }^{+} \mathrm{T}$ cells in lung and BAL fluid samples were significantly higher in the $\mathrm{Cd}+$ RSV group than those in the RSV alone group. $\mathrm{CD}^{+} \mathrm{T}$ cells were significantly higher in the $\mathrm{Cd}+\mathrm{RSV}$ group compared with RSV alone for BAL fluid, but the increase was not significant in the lung.

Previous research showed that higher $\mathrm{Cd}$ burden and longer duration of $\mathrm{Cd}$ exposure increased NF- $\kappa \mathrm{B}-\mathrm{de}-$ pendent cytokine expression. ${ }^{20}$ Analyses of IFN- $\gamma$ and proinflammatory cytokines IL-1 $\beta$, IL-6, and IL-4 showed a promoting trend of $\mathrm{Cd}$ pre-exposure on RSV-related responses in both lung and BAL fluid, but the increases were not statistically significant (Figure 3, A-H). Similarly, the chemokine KC levels were mostly dependent on RSV infection and not significantly increased by pretreatment with Cd (Figure 4, A and C). In contrast, the chemokine RANTES after RSV infection was significantly enhanced by $\mathrm{Cd}$ pre-exposure in both lung tissue and airway BAL fluid samples (RSV versus Cd + RSV) (Figure 4, B and D). Together with the histologic data and T-cell counts, the results show that $\mathrm{Cd}$ pre-exposure increased production of RANTES chemokine in the airways and lungs on RSV infection, with associated infiltration of eosinophils, monocytes, and lymphocytes.

\section{HRM Identifies Global Metabolic Responses to Cd Exposure and/or RSV Infection}

As shown above, Cd potentiation effects on inflammatory response to RSV infection are evident, yet metabolic responses associated with inflammation are not well studied.
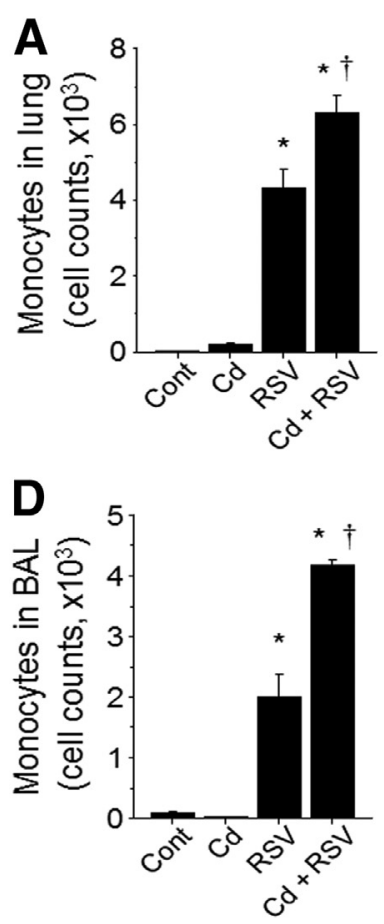
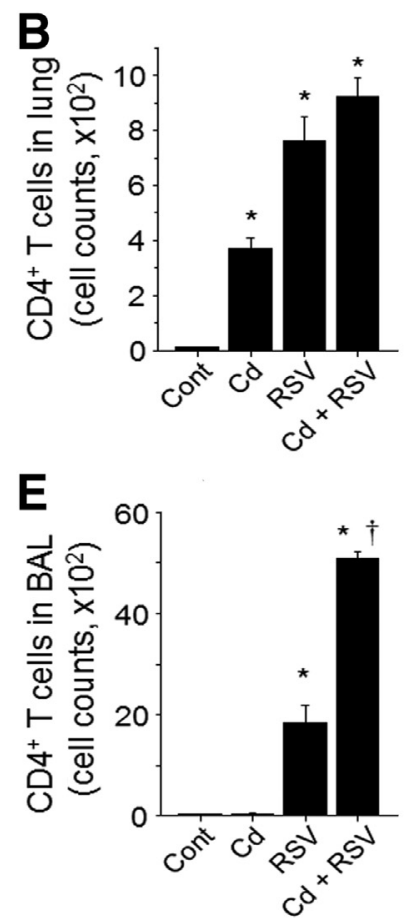

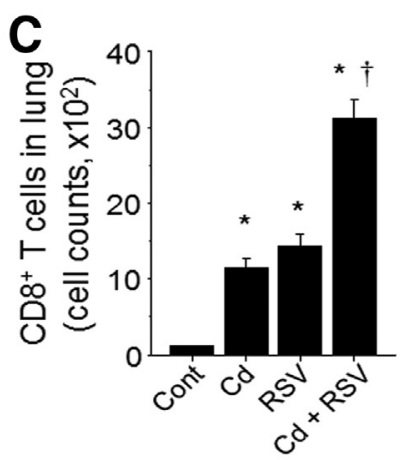

$\mathbf{F}$

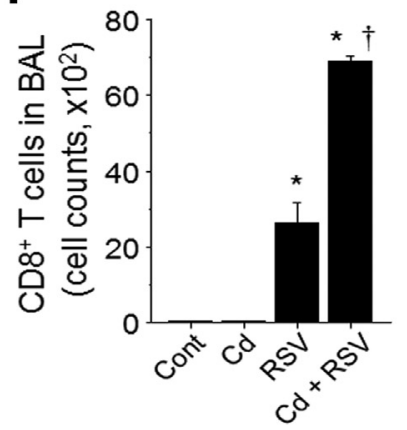

Figure 2 Cadmium (Cd)-promoted infiltration of monocytes and lymphocytes in lung. The lung tissues (A-C) and bronchoalveolar lavage (BAL) fluid

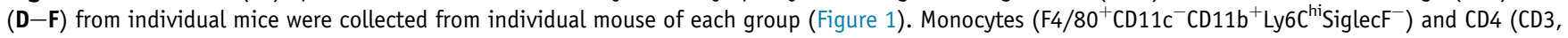
CD4) and CD8 (CD3, CD8) lymphocytes were analyzed by flow cytometry, and quantified cells are shown in bar graphs using an unpaired two-tailed $t$-test. Error bars indicate means \pm SEM of cell counts from individual animals $(\mathbf{A}-\mathbf{F}) . n=8$ per group $(\mathbf{A}-\mathbf{F}) .{ }^{*} P<0.05$ versus control (cont); ${ }^{\dagger} P<0.05$ versus respiratory syncytial virus (RSV) only group. 


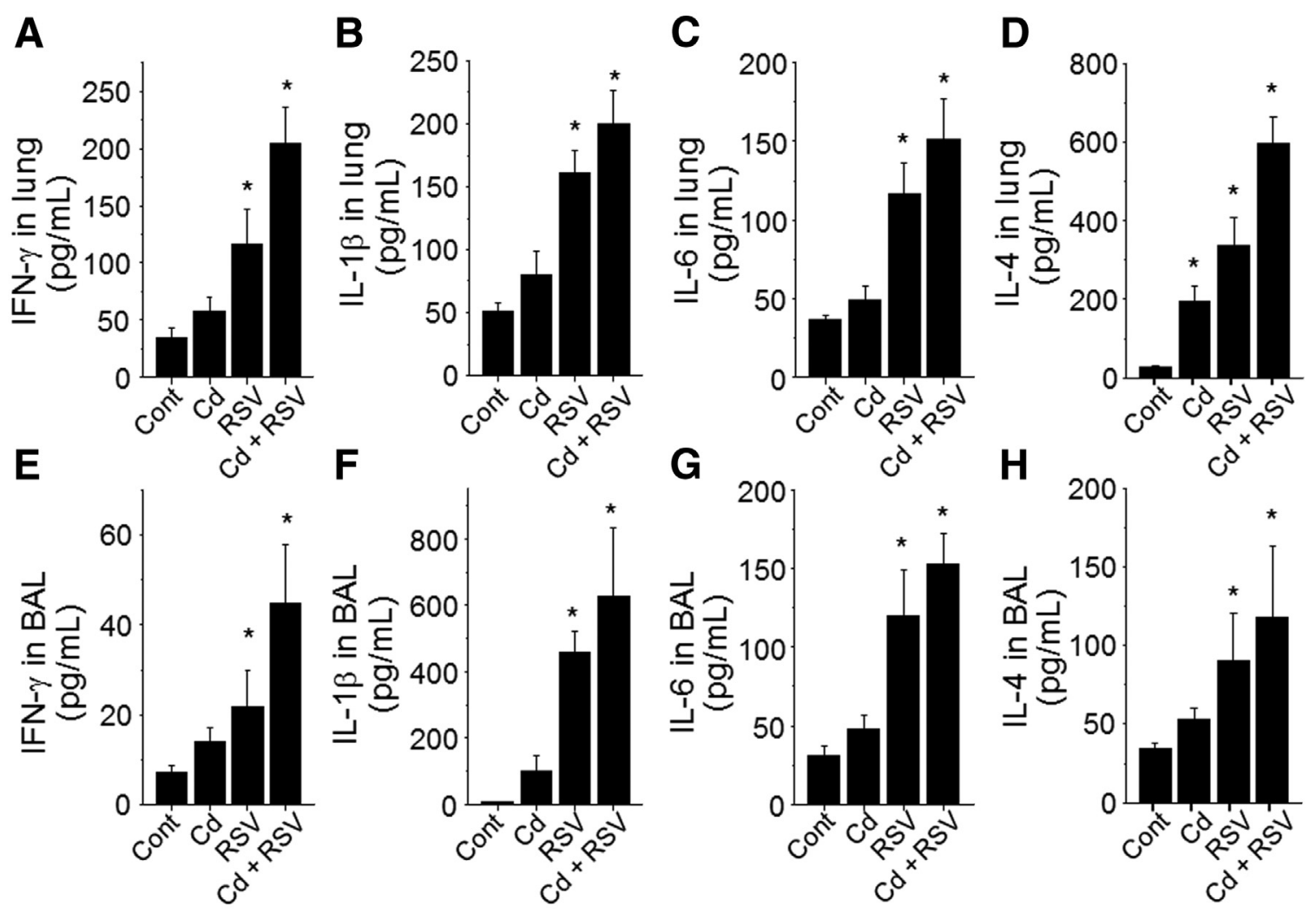

Figure 3 Cadmium (Cd) intake enhanced proinflammatory cytokine levels in the lung after respiratory syncytial virus (RSV) infection. Inflammatory cytokines were determined in lung lysates and bronchoalveolar lavage (BAL) fluids and analyzed for interferon (IFN)- $\gamma(\mathbf{A}$ and $\mathbf{E})$, IL-1 $1 \beta$ (B and F), IL-6 (C and G), and IL-4 (D and $\mathbf{H})$ quantitation by corresponding cytokine enzyme-linked immunosorbent assay kits. Data are expressed as means \pm SEM $(\mathbf{A}-\mathbf{H}) . n=8$ per group $(\mathbf{A}-\mathbf{H}) .{ }^{*} P<0.05$ versus control (cont).

Before investigation of Cd-potentiated metabolic disruption caused by RSV infection-caused inflammation, global metabolic response to Cd burden and/or RSV infection was examined using HRM data for all four groups of lung ( $n=8$ per group) and BAL fluid ( $n=8$ per group). Mass spectral data preprocessing yielded total 11,280 and 7809 metabolic features in lung and BAL fluid samples, respectively, from four conditions (control, Cd, RSV, and Cd + RSV). Analysis of variance showed 1358 of 11,280 lung and 551 of 7809 BAL fluid metabolites were changed by $\mathrm{Cd}$, RSV, and Cd + RSV exposures at $P<0.05$ (without adjustment for multiple comparisons; see below). Results of
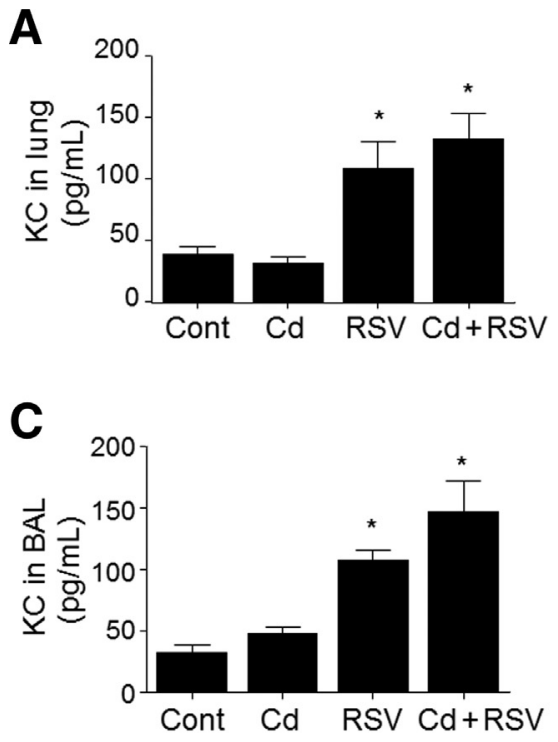

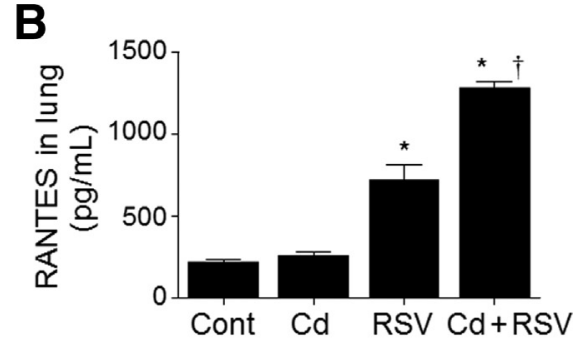

D

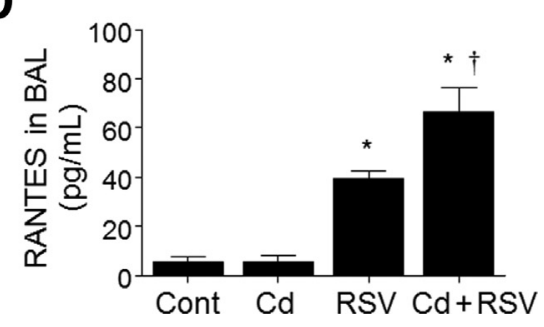

Figure 4 Cadmium (Cd) pre-exposure enhanced chemokine regulated on activation, normal $T$ cells expressed and secreted (RANTES), and keratinocyte cytokine $(\mathrm{KC})$ production after respiratory syncytial virus (RSV) infection. Chemokines were determined in lung lysates and bronchoalveolar lavage (BAL) fluid, as described in Materials and Methods, and analyzed for KC (A and C) and RANTES (B and D) quantification by enzyme-linked immunosorbent assay. Data are expressed as means \pm SEM (A-D). $n=8$ per group $(\mathbf{A}-\mathbf{D}) .{ }^{*} P<0.05$ versus control (cont); ${ }^{\dagger} P<0.05$ versus RSV only. 
hierarchical clustering analysis-heat map and principal component analysis plots using these raw data show that the BAL fluid metabolites completely separate RSV from nonRSV groups and also separated RSV $+\mathrm{Cd}$ from RSV (Supplemental Figure S2). Results were similar for metabolites in lung extracts, but groups were not as well separated (Supplemental Figure S2, A and C). Pathway enrichment analysis on the 1358 lung metabolites using Mummichog ${ }^{33}$ showed that metabolic pathways of connective tissues (amino sugars and sialic acid), nitric oxide signaling (biopterin), surfactant production (glycerophospholipid), immune signaling (tryptophan metabolism), and microcirculation (purine metabolism) were altered by $\mathrm{Cd}$, RSV infection, and Cd + RSV (Supplemental Figure S2B). The results of the 551 BAL fluid metabolites also showed that biopterin metabolism was changed; in addition, mitochondrial metabolism (carnitine shuttle) and oxidative stress (methionine and cysteine metabolism) were affected by $\mathrm{Cd}$, RSV, and Cd + RSV (Supplemental Figure S2D). To determine contributing factor (Cd and/or RSV) to pathway disruption, lung and BAL fluid HRM data was compared between each group. Pathways affected by Cd included Trp, Met, Cys, and carnitine shuttle (Table 1).

\section{Cd Pre-Exposure Potentiates Metabolic Disruption on RSV Infection}

To more specifically analyze $\mathrm{Cd}$ potentiation of metabolic responses to RSV, targeted HRM data analysis was performed comparing only RSV and Cd + RSV groups using lung ( $n=8$ per group) and BAL fluid ( $n=8$ per group) HRM data. Data preprocessing yielded total 10,934 lung and 7977 BAL fluid metabolic features. Of these features, 320 (147 higher and 173 lower in Cd + RSV) lung and 60 (24 lower and 36 higher in Cd + RSV) BAL fluid metabolites were different in their abundance comparing between RSV and Cd + RSV $(P<0.05)$. Details of these metabolites are provided in Supplemental Table S1, including changes in amino acids and mitochondrial intermediates.
Unsupervised hierarchical clustering analysis showed that there were differences in these metabolites between RSV and Cd + RSV (Figure 5, A and C). Metabolic pathway enrichment results using Mummichog are shown in Figure 5, B and D. Most notably, the lung metabolic pathways included purine and pyrimidine, amino acids (Met and Cys, Asp and Asn, Tyr, Val and Leu, Lys, and Trp), selenoamino acid, and lipids (glycerophospholipid, cholesterol, and glycosphingolipid). In addition, pathways of pyrimidine and carnitine shuttle were identified using 60 BAL fluid metabolites. The results of this targeted analysis comparing $\mathrm{RSV}$ and Cd + RSV revealed the metabolic differences as a result of $\mathrm{Cd}$ with the presence of RSV-induced metabolic alterations; and they confirm the pathway results from global untargeted analysis in showing that $\mathrm{Cd}$ pre-exposure exacerbates effect of RSV infection on oxidative stress pathways (Met and Cys), immune signaling (Trp pathway), and mitochondrial fatty acid metabolism (carnitine shuttle) (Table 1).

\section{Low-Dose Cd Causes Low Grade of Inflammation and} Exacerbates Inflammation Caused by RSV via IL-4

To better understand the mechanism of Cd-potentiating RSV effects, xMWAS software, ${ }^{35}$ a data integration and differential network analysis tool to integrate the data of metabolomics and inflammation, was used. This approach enabled systems-level evaluation of $\mathrm{Cd}$ effects and visualization of difference of inflammatory responses between $\mathrm{Cd}$ alone, $\mathrm{RSV}$, and Cd + RSV groups. Integrative analysis was performed on metabolome ( 8 samples $\times 11,341$ metabolic features) and nine inflammatory markers $\left(\mathrm{CD} 4^{+} \mathrm{T}\right.$ cells, $\mathrm{CD} 8^{+} \mathrm{T}$ cells, monocytes, KC, RANTES, IFN- $\gamma$, IL-1, IL-6, and IL-4). The result of network structure of inflammation $\times$ metabolite interaction showed that in Cdtreated mouse lung but not in control mice, IL-4 and its associated metabolites $(|\rho| \geq 0.7)$ formed a distinct cluster separated from the rest of inflammation markers and metabolites (Figure 6A). This unique IL-4 cluster was not present in

Table 1 Top Metabolic Pathways of Metabolome Different between Four Groups

\begin{tabular}{lllll}
\hline Lung or BAL fluid & Cd vs control & RSV vs control & Cd + RSV vs control & Cd + RSV vs RSV \\
\hline Lung $(n=11,280)$ & Total (360): & Total (1289): & Total (1190): & Total (320): \\
& biopterin (4) & aminosugars (14) & aminosugars (25) & purine (9) \\
& vitamin A (3) & sialic acid (10) & biopterin (11) & carnitine shuttle (14) \\
& sialic acid (4) & biopterin (6) & glycerophospholipid (15) & \\
& tryptophan (5) & glycerophospholipid (15) & glasteine (7) \\
& & purine (15) & tryptophan (15) & biopterin (5) \\
BAL fluid $(n=7809)$ & Total (297): & Total (456): & purine (14) & Total (60): \\
& biopterin (2) & biopterin (2) & biopterin (2) & pyrimidine (3) \\
& histidine (2) & urea cycle (4) & carnitine shuttle (6) & carnitine shuttle (4) \\
\hline
\end{tabular}

Numbers of metabolites associated with pathways are listed in parentheses. Pathways that consistently reflected Cd effect in various treatment groups are in bold. $\mathrm{BAL}$, bronchoalveolar lavage; Cd, cadmium; RSV, respiratory syncytial virus. 

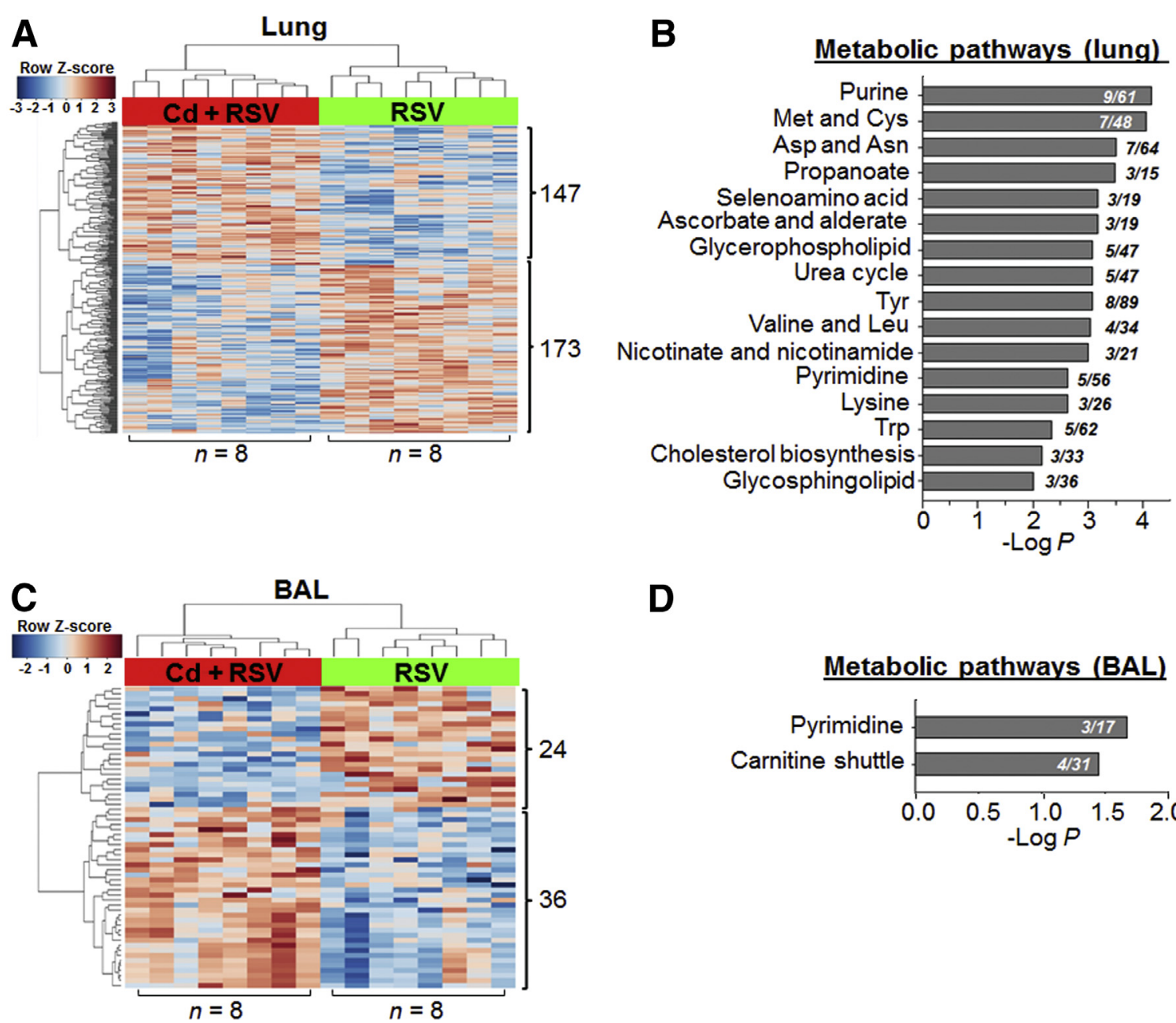

D

\section{Metabolic pathways (BAL)}

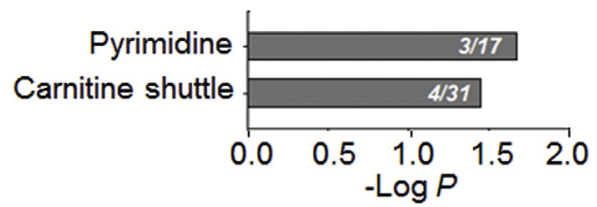

36

Figure 5 Lung (A) and bronchoalveolar lavage (BAL) fluid (C) metabolic features that differed between cadmium (Cd) + respiratory syncytial virus (RSV) and RSV treatment (limma test, $P<0.05$ ) allow group separation by two-way unsupervised hierarchical clustering analysis and are shown to be enriched in metabolic pathways (B and $\mathbf{D}$ ) by Mummichog analysis. Numbers in metabolic pathways (B and $\mathbf{D}$ ) indicate the overlap size (ie, number of significant metabolites relative to the total number of metabolites detected in the pathway). $n=8$ mice per group (A and $\mathbf{C}$ ).

the RSV group (Figure 6B), but was preserved in the $\mathrm{Cd}+\mathrm{RSV}$ group (Figure 6C). Metabolites associated with this cluster included intermediates from Met and Cys metabolic pathway, such as S-adenosylmethioninamine, Cys, cysteic acid, as well as mitochondrial fatty acid metabolism intermediates (Figure 6 and Supplemental Table S2).

To examine the specificity of Cd-potentiating effect on lung inflammation by RSV infection, association of other metals with inflammation markers. Integrative analysis $(11,341$ metabolic features $\times 9$ inflammatory markers $)$ was performed in the Cd $+\mathrm{RSV}$ group $(n=8 ;|\rho|>0.8)$ with 10 metals of possible importance in lung injury and nutrition, including ${ }^{55} \mathrm{Mn},{ }^{24} \mathrm{Mg},{ }^{27} \mathrm{Al},{ }^{51} \mathrm{~V},{ }^{52} \mathrm{Cr},{ }^{58} \mathrm{Ni},{ }^{98} \mathrm{Mo}$, ${ }^{134} \mathrm{Ba},{ }^{77} \mathrm{Se}$, and ${ }^{64} \mathrm{Zn}$. The network structure showed a strong interaction of ${ }^{114} \mathrm{Cd},{ }^{77} \mathrm{Se}$, and ${ }^{64} \mathrm{Zn}$ with $\mathrm{IL}-4$ and metabolome community (Figure 7 and Supplemental Table S3). This integration analysis confirmed the result of Figure 6 that $\mathrm{Cd}$ resulted in association of IL-4 with metabolic alteration. Moreover, the result showed that ${ }^{55} \mathrm{Mn}$,
${ }^{24} \mathrm{Mg},{ }^{27} \mathrm{Al},{ }^{51} \mathrm{~V},{ }^{52} \mathrm{Cr},{ }^{58} \mathrm{Ni},{ }^{98} \mathrm{Mo}$, and ${ }^{134} \mathrm{Ba}$ did not interact with IL-4, whereas ${ }^{64} \mathrm{Zn}$ and ${ }^{77} \mathrm{Se}$ showed strong interaction with IL-4, suggesting an interaction of $\mathrm{Cd}$ with $\mathrm{Zn}$ and Se in potentiating RSV-induced inflammation.

\section{Discussion}

Severity of response to viral infection is potentiated by several exposures, such as cigarette smoking, secondhand smoke, and air pollution ${ }^{8,43,44}$; and public health policies are developed to address these concerns. Dietary exposures that can potentiate severity of lung injury, however, are less well studied. In humans who do not smoke, diet is the primary source of $\mathrm{Cd}$. To determine effects of dietary levels of $\mathrm{Cd}$, oral $\mathrm{Cd}$ exposures were used in mice, ranging from 1 to 10 $\mathrm{mg} / \mathrm{L}$ drinking water, to achieve lung $\mathrm{Cd}$ contents found in human lung of nonsmokers. ${ }^{45}$ On the basis of this study, there appears to be a dose-response effect over the range of 

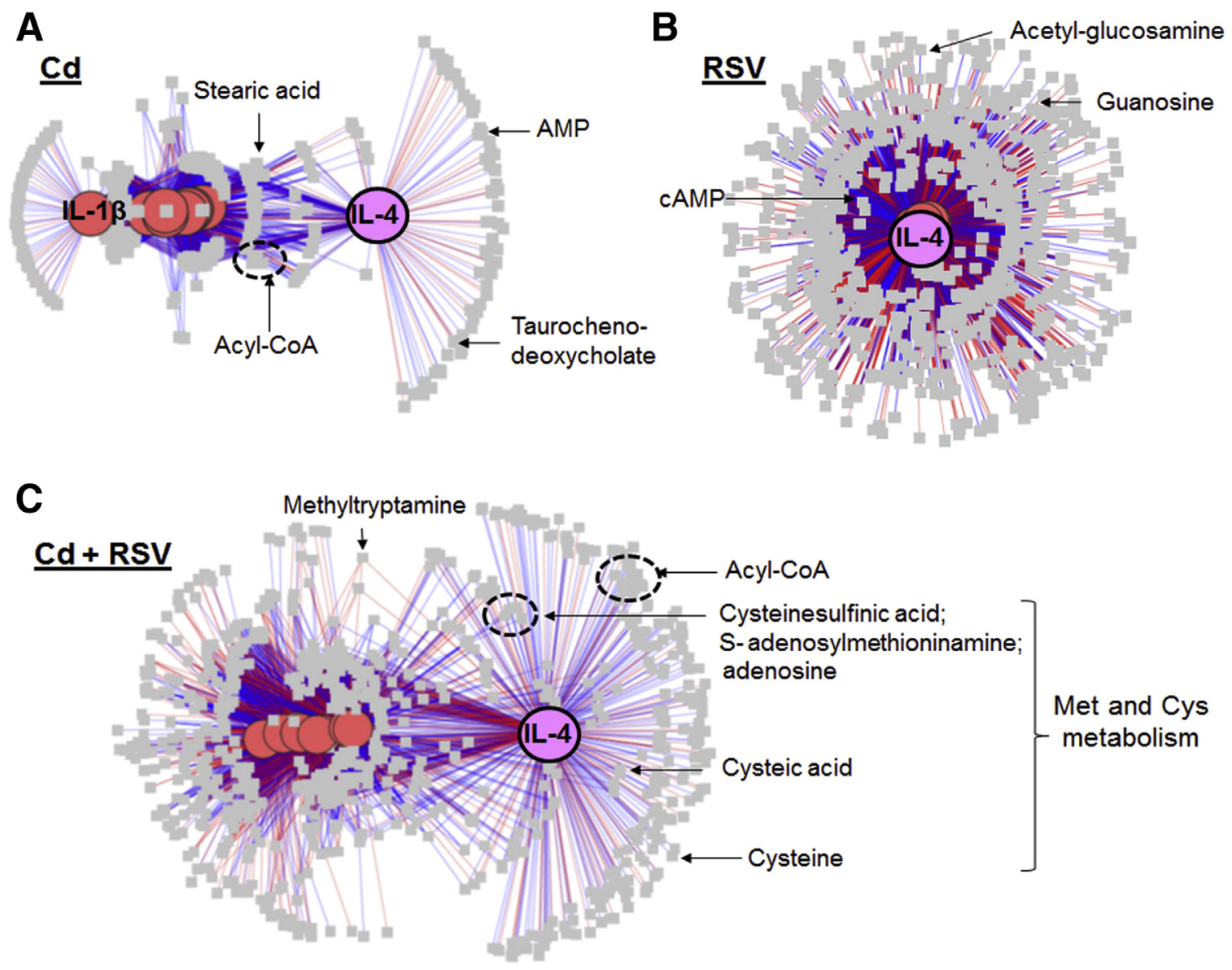

Figure 6 Network structure of metabolome interacting with inflammatory markers in mice treated with cadmium (Cd; A), respiratory syncytial virus (RSV; B), and Cd + RSV (C). Association between nine inflammatory markers (pink or purple circle) and the metabolome (11,341 features; gray squares) from mouse lung are visualized at $|\rho| \geq 0.7$, showing a distinct IL-4 and metabolite hub in mouse lung treated with Cd or Cd + RSV. Red edge indicates positive association; blue indicates negative association. Details of metabolite annotation can be found in Supplemental Table S2. Not shown: control mice with low Cd showed no network correlation of Cd and IL-4. $n=8(\mathbf{A}-\mathbf{C})$.

$\mathrm{Cd}$ found in lungs of nonsmoking humans. In our previous study of $10 \mathrm{mg} / \mathrm{L}$ for 20 weeks, mice had airway hyperresponsiveness and disrupted neuronal pathways regulating bronchial tone. ${ }^{25} \mathrm{~A}$ transcriptome-metabolome-wide association study of Cd further showed enriched olfactory, glutamatergic, cholinergic, and serotonergic gene sets, with greatest enrichment in olfactory receptors regulating chemosensory function and airway hypersensitivity. Targeted metabolomics showed that Cd treatment increased metabolites in pathways of glutamatergic (glutamate), serotonergic (tryptophan), cholinergic (choline), and catecholaminergic (tyrosine) receptors in the lung; and protein abundance measurements showed that the glutamate receptor glutamate ionotropic receptor NMDA type subunit 2A (GRIN2A) was increased. These results establish a Cd-dependent mechanism that could exacerbate asthma linked to RSV. ${ }^{25}$ Thus, the present study showing potentiation of lung inflammation at relevant lung $\mathrm{Cd}$ burden ${ }^{40-42}$ further emphasizes the potential for environmental Cd to worsen outcomes of RSV infection. Because $\mathrm{Cd}$ burden increases with age, this mechanism could also contribute to increased morbidity and mortality due to RSV infection and asthma development in humans at older ages. ${ }^{5,46-48}$

The present results showed that low-dose $\mathrm{Cd}$ preexposure resulted in significant increases in lung viral titers, overall histopathology, mucus production, and eosinophilic infiltration because of RSV infection. Enhanced histopathology appeared to be correlated with cellular infiltrates, including lymphocytes, monocytes, and neutrophils (data not shown), into the airways as well as the high levels of chemokines (RANTES and KC) and cytokines (IFN- $\gamma$, IL-1 $\beta$, IL-6, and IL-4) in the lungs from the mice with $\mathrm{Cd}$ pre-exposure. A recent study using human samples demonstrated that adults with severe RSV illness and high viral loads requiring hospitalization responded to induce robust CD4 and CD8 T cells secreting IFN- $\gamma$ and other cytokines, suggesting T-cell responses linked to disease severity. ${ }^{6}$ RSV replication is associated with producing chemokines RANTES and KC, which are known to promote the recruitment of monocytes and immature dendritic cells. ${ }^{49,50}$ In particular, chemokine (C$\mathrm{C}$ motif) ligand 5/RANTES is a key proinflammatory 


\section{Inflammation $\times$ Metabolite $\times$ Metal}

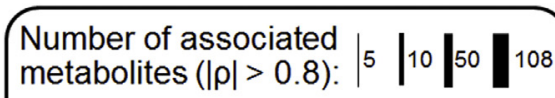

No common metabolite with:

$\mathrm{Mn}, \mathrm{Mg}, \mathrm{Al}, \mathrm{V}, \mathrm{Cr}, \mathrm{Ni}, \mathrm{Mo}$, and $\mathrm{Ba}$

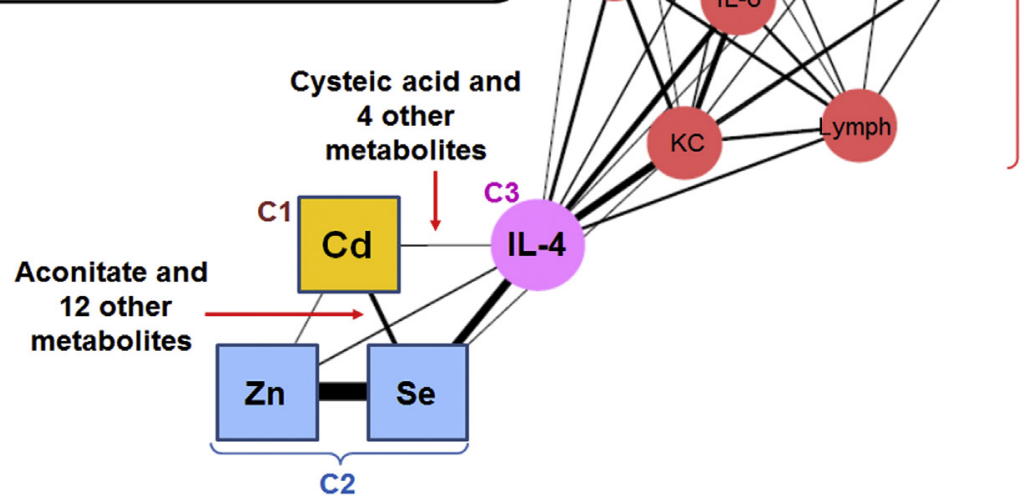

Figure 7 Network structure of metals interacting with inflammatory markers through common metabolic associations in mouse lung treated with cadmium + respiratory syncytial virus. Association among 9 inflammatory markers (circle), 11 metals (squares), and the metabolome (11,341 features; data not shown) from mouse lung $(|\rho|>0.8)$ were integrated using xMWAS. The number of commonly associated metabolites between two elements (metal or marker) was reflected by the width of edges connecting the two elements, showing a strong interaction of ${ }^{114} \mathrm{Cd}$, ${ }^{77} \mathrm{Se}$, and ${ }^{64} \mathrm{Zn}$ with IL-4 but not with other inflammation markers. Metals that did not share metabolite association with IL-4 were excluded from the network. Details of metabolites in community (C1 to C4) and annotation of metabolites can be found in Supplemental Table S3. For simplicity, isotopic information of metals are omitted (see Materials and Methods for details). $n=8$. IFN- $\gamma$, interferon- $\gamma$; KC, keratinocyte cytokine; RANTES, regulated on activation, normal T cells expressed and secreted.

chemokine produced by RSV-infected epithelial cells, activating and recruiting monocyte, eosinophil, and lymphocyte CD4 and CD8 $\mathrm{T}$ cells into the airway space. ${ }^{51,52}$ It was also reported that RSV-induced chemokine (C-C motif) ligand 5/RANTES contributes to exacerbation of allergic airway inflammation. ${ }^{53}$ The present results show both mitochondrial and oxidative stress effects that could promote inflammation signaling, even though low-dose $\mathrm{Cd}$ pre-exposure did not cause any abnormal or illness symptoms in mice.
To examine the effects of $\mathrm{Cd}$ burden in lung inflammation by RSV infection, a mouse model was designed that was pre-exposed to $\mathrm{Cd}$ at a low dose $(3.3 \mathrm{mg} / \mathrm{L})$ for only 4 weeks, thereby resulting in less $\mathrm{Cd}$ accumulation in lung than in previous studies showing stimulated inflammation and fibrosis signaling. ${ }^{20,25,45,54,55}$ Compared with higher levels of $\mathrm{Cd}$ exposures, reliable detection of functional changes associated with $\mathrm{Cd}$ exposures is difficult because pathologic indicators of altered lung function, such as respiratory tract distress, are profound and make minor changes

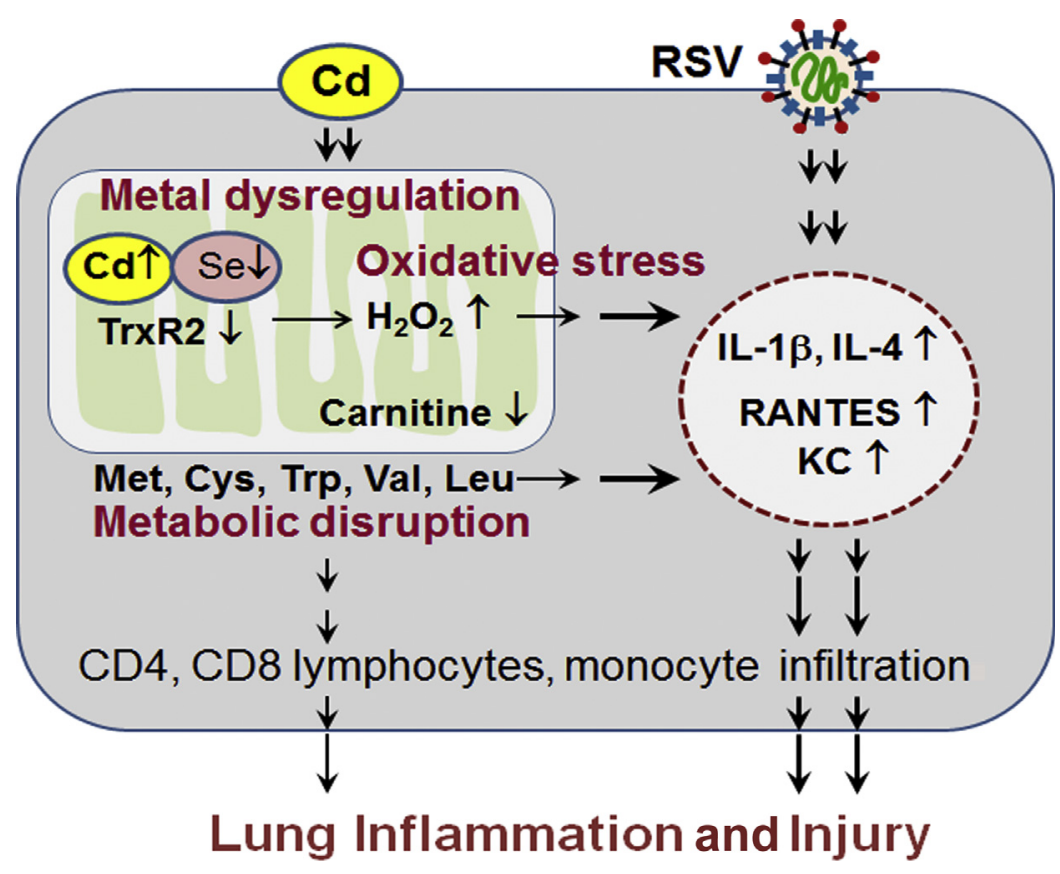

Figure 8 Proposed schematic diagram: cadmium (Cd) -potentiated inflammation by respiratory syncytial virus (RSV) infection. Low-dose Cd-potentiated RSV infection caused lung inflammation and injury by dysregulating metals, disrupting mitochondrial metabolism, stimulating oxidative stress, and elevating proinflammatory cytokines, chemokines, and infiltration of immune cells. KC, keratinocyte cytokine; RANTES, regulated on activation, normal T cells expressed and secreted; TrxR2, thioredoxin reductase 2. 
appear unimportant. Nonetheless, histopathology (hematoxylin and eosin staining) (Figure 1), $\mathrm{CD}^{+}$cells (Figure 2B), $\mathrm{CD}^{+}$cells (Figure 2C), and IL-4 (Figure 3, D and $\mathrm{H})$ show effects of $\mathrm{Cd}(P<0.05)$. On the basis of this, one may speculate that inflammation could occur as a consequence of $\mathrm{Cd}$ in nonsmoking humans, but this effect may be difficult to separate from confounding factors. More importantly, in the mouse model, this relatively subtle change by $\mathrm{Cd}$ was supported by the results of integrative functional network analysis by incorporating metabolic change and inflammation markers (Figure 6A), and provided the information that $\mathrm{Cd}$ caused IL-4 elevation and subsequent alterations in metabolites.

Interaction of IL-4 with $\mathrm{Zn}$ has been previously reported via mechanisms dependent on metallothioneins and metal transporter. ${ }^{56,57}$ Interestingly, it was shown that increase in Zn may promote pathogen persistence in macrophages, indicating a fundamental role of metal metabolism in shaping the immune response. ${ }^{56} \mathrm{IL}-4$ elevation by $\mathrm{Cd}$ supports our previous study of $\mathrm{Cd}$-increased airway reactivity. ${ }^{25}$ IL-4 is known as a central cytokine in the development of inflammatory response in allergies and asthma. ${ }^{58,59}$ In particular, RSV infection in infancy has been shown to enhance type 2 helper T-cell sensitization via IL-4 in children, thus predisposing them to subsequent allergy and asthma development. ${ }^{59,60}$ In this study, Cd increased IL-4 and potentiated inflammation by RSV infection via IL-4, and this inflammation mechanism was exclusive to $\mathrm{Cd}$, $\mathrm{Zn}$, and Se but not to $\mathrm{Mn}, \mathrm{Mg}, \mathrm{Al}, \mathrm{V}, \mathrm{Cr}, \mathrm{Ni}, \mathrm{Mo}$, or $\mathrm{Ba}$ (Figure 7). Future studies are warranted to determine whether these interactions are important in severity of RSV responses in humans.

The metabolic pathway of Trp is associated with proinflammatory cytokine response and immune cell production by virus infection. ${ }^{21,61,62}$ Consistently, our data also showed that the Trp pathway is one of the critical metabolic pathways associated with enhancing inflammation by $\mathrm{Cd}$ (Table 1 and Figure 5C). In addition, in our previous study of acute $\mathrm{Cd}$ toxicity, $\mathrm{Cd}$ treatment had a critical effect on changes in branched-chain amino acids and carnitine metabolites in mouse liver. ${ }^{63}$ Notably, the present study also shows such effect of $\mathrm{Cd}$ on lung metabolism in that valine, leucine, and isoleucine degradation pathway from lung and carnitine shuttle pathway from BAL fluid were significant pathways, as supported by HRM data comparison between the Cd + RSV and RSV groups (Figure 5C). These results establish that mitochondrial metabolic disruption is a factor mediating elevated inflammatory response to $\mathrm{Cd}$ preexposure, followed by RSV infection.

$\mathrm{Cd}$ has widespread effects on cell functions due to inhibition of key oxidation-reduction regulatory selenoproteins, thioredoxin reductases, and glutathione peroxidases. Co-administration of a nutritionally relevant $\mathrm{Se}$ dose decreases lung $\mathrm{Cd}$ and protects against $\mathrm{Cd}$ effects on lung transcriptome and metabolome. ${ }^{54}$ In a separate study of examining metals in human lung tissues, negative association was found with lung Se and lung mitochondrial Se content (M. Ryan Smith, unpublished data). These results support the principle that Cd-metal interactions occur at environmentally relevant $\mathrm{Cd}$ and nutritionally relevant Se exposures. Given this principle, enhanced inflammation observed in the Cd + RSV group could be associated more broadly with mitochondrial metal dysregulation (Figure 8).

In summary, enhanced lung inflammation from RSV infection occurred at low $\mathrm{Cd}$ burden relevant to natural $\mathrm{Cd}$ accumulation in human lungs from dietary exposure. The results show that environmental $\mathrm{Cd}$ is likely an interacting toxicologic factor in severity of human pulmonary disease due to viral pathogens. Cd caused a broad range of metabolic disruption, including purine and pyrimidine metabolism, glycerophospholipids, and amino acid metabolism. Perhaps most important, HRM shows altered mitochondrial metabolism with effects on branched-chain amino acid metabolism and carnitine shuttle. The results support a role for mitochondrial oxidant potentiation of inflammation in addition to previously described $\mathrm{Cd}$-dependent nuclear proinflammatory signaling. Conclusively, the present study addresses the challenge to define the role of environmental $\mathrm{Cd}$ toxicity in the lungs at levels in individuals without occupational or smoking-related exposures and heightens need for research to evaluate dietary $\mathrm{Cd}$ burden as a contributing factor to RSV severity in humans.

\section{Acknowledgments}

Y.-M.G, D.P.J., and S.-M.K. discussed and designed experiments; X.H., K.-h.K., Y.L., J.F., M.S.R., Y.-J.J., and M.O. performed experiments; X.H., K.-h.K., Y.L., S.-M.K., Y.-M.G., and D.P.J. analyzed and interpreted data; X.H., K.-h.K., Y.L., S.-M.K., D.P.J., and Y.-M.G. prepared and edited the manuscript text; all authors reviewed the manuscript.

\section{Supplemental Data}

Supplemental material for this article can be found at http://doi.org/10.1016/j.ajpath.2019.04.013.

\section{References}

1. Falsey AR, Hennessey PA, Formica MA, Cox C, Walsh EE: Respiratory syncytial virus infection in elderly and high-risk adults. N Engl J Med 2005, 352:1749-1759

2. Hall CB, Weinberg GA, Blumkin AK, Edwards KM, Staat MA, Schultz AF, Poehling KA, Szilagyi PG, Griffin MR, Williams JV, Zhu Y, Grijalva CG, Prill MM, Iwane MK: Respiratory syncytial virus-associated hospitalizations among children less than 24 months of age. Pediatrics 2013, 132:e341-e348

3. Zhou H, Thompson WW, Viboud CG, Ringholz CM, Cheng PY, Steiner C, Abedi GR, Anderson LJ, Brammer L, Shay DK: Hospitalizations associated with influenza and respiratory syncytial virus in the United States, 1993-2008. Clin Infect Dis 2012, 54:1427-1436 
4. Nair H, Nokes DJ, Gessner BD, Dherani M, Madhi SA, Singleton RJ, O'Brien KL, Roca A, Wright PF, Bruce N, Chandran A, Theodoratou E, Sutanto A, Sedyaningsih ER, Ngama M, Munywoki PK, Kartasasmita C, Simoes EA, Rudan I, Weber MW, Campbell H: Global burden of acute lower respiratory infections due to respiratory syncytial virus in young children: a systematic review and meta-analysis. Lancet 2010, 375:1545-1555

5. Knudson CJ, Varga SM: The relationship between respiratory syncytial virus and asthma. Vet Pathol 2015, 52:97-106

6. Roumanes D, Falsey AR, Quataert S, Secor-Socha S, Lee FE, Yang H, Bandyopadhyay S, Holden-Wiltse J, Topham DJ, Walsh EE: T-cell responses in adults during natural respiratory syncytial virus infection. J Infect Dis 2018, 218:418-428

7. Sundaram ME, Meece JK, Sifakis F, Gasser RA Jr, Belongia EA: Medically attended respiratory syncytial virus infections in adults aged $>/=50$ years: clinical characteristics and outcomes. Clin Infect Dis 2014, 58:342-349

8. Bhatt JM, Everard ML: Do environmental pollutants influence the onset of respiratory syncytial virus epidemics or disease severity? Paediatr Respir Rev 2004, 5:333-338

9. Faroon O, Ashizawa A, Wright S, Tucker P, Jenkins K, Ingerman L, Rudisill C: Toxicological Profile for Cadmium. Edited by SERVICES USDOHAH. Atlanta, GA: ATSDR, Division of Toxicology and Human Health Sciences, 2012

10. Hassan F, Xu X, Nuovo G, Killilea DW, Tyrrell J, Da Tan C, Tarran R, Diaz P, Jee J, Knoell D, Boyaka PN, Cormet-Boyaka E: Accumulation of metals in GOLD4 COPD lungs is associated with decreased CFTR levels. Respir Res 2014, 15:69

11. Ganguly K, Levanen B, Palmberg L, Akesson A, Linden A: Cadmium in tobacco smokers: a neglected link to lung disease? Eur Respir Rev 2018, 27. 170122

12. Satarug S, Moore MR: Adverse health effects of chronic exposure to low-level cadmium in foodstuffs and cigarette smoke. Environ Health Perspect 2004, 112:1099-1103

13. Suwazono $\mathrm{Y}$, Kido $\mathrm{T}$, Nakagawa $\mathrm{H}$, Nishijo $\mathrm{M}$, Honda $\mathrm{R}$, Kobayashi E, Dochi M, Nogawa K: Biological half-life of cadmium in the urine of inhabitants after cessation of cadmium exposure. Biomarkers 2009, 14:77-81

14. Ruiz P, Mumtaz M, Osterloh J, Fisher J, Fowler BA: Interpreting NHANES biomonitoring data, cadmium. Toxicol Lett 2010, 198: $44-48$

15. Rosa C, Blake JE, Bratton GR, Dehn LA, Gray MJ, O'Hara TM: Heavy metal and mineral concentrations and their relationship to histopathological findings in the bowhead whale (Balaena mysticetus). Sci Total Environ 2008, 399:165-178

16. Wormser U, Nir I: Effect of age on cadmium-induced metallothionein synthesis in the rat. Arch Toxicol 1988, 62:392-394

17. Go YM, Orr M, Jones DP: Actin cytoskeleton redox proteome oxidation by cadmium. Am J Physiol Lung Cell Mol Physiol 2013, 305:L831-L843

18. Go YM, Orr M, Jones DP: Increased nuclear thioredoxin-1 potentiates cadmium-induced cytotoxicity. Toxicol Sci 2013, 131:84-94

19. Go YM, Son DJ, Park H, Orr M, Hao L, Takabe W, Kumar S, Kang DW, Kim CW, Jo H, Jones DP: Disturbed flow enhances inflammatory signaling and atherogenesis by increasing thioredoxin-1 level in endothelial cell nuclei. PLoS One 2014, 9:e108346

20. Chandler JD, Hu X, Ko E, Park S, Jolyn Fernandes J, Lee Y-T, Orr ML, Hao L, Smith MR, Neujahr DC, Uppal K, Kang S-M, Jones DP, Go Y-M: Low-dose cadmium potentiates lung inflammatory response to 2009 pandemic H1N1 influenza virus in mice. Environ Int 2018, 127:720-729

21. Chandler JD, Hu X, Ko EJ, Park S, Lee YT, Orr M, Fernandes J, Uppal K, Kang SM, Jones DP, Go YM: Metabolic pathways of lung inflammation revealed by high-resolution metabolomics (HRM) of H1N1 influenza virus infection in mice. Am J Physiol Regul Integr Comp Physiol 2016, 311:R906-R916
22. Cribbs SK, Park Y, Guidot DM, Martin GS, Brown LA, Lennox J, Jones DP: Metabolomics of bronchoalveolar lavage differentiate healthy HIV-1-infected subjects from controls. AIDS Res Hum Retroviruses 2014, 30:579-585

23. Alvarez JA, Chong EY, Walker DI, Chandler JD, Michalski ES, Grossmann RE, Uppal K, Li S, Frediani JK, Tirouvanziam R, Tran VT, Tangpricha V, Jones DP, Ziegler TR: Plasma metabolomics in adults with cystic fibrosis during a pulmonary exacerbation: a pilot randomized study of high-dose vitamin D3 administration. Metabolism 2017, 70:31-41

24. Jones DP, Walker DI, Uppal K, Rohrbeck P, Mallon CT, Go YM: Metabolic pathways and networks associated with tobacco use in military personnel. J Occup Environ Med 2016, 58:S111-S116

25. Chandler JD, Wongtrakool C, Banton SA, Li S, Orr ML, Barr DB, Neujahr DC, Sutliff RL, Go YM, Jones DP: Low-dose oral cadmium increases airway reactivity and lung neuronal gene expression in mice. Physiol Rep 2016, 4. e12821

26. Hwang HS, Kwon YM, Lee JS, Yoo SE, Lee YN, Ko EJ, Kim MC, Cho MK, Lee YT, Jung YJ, Lee JY, Li JD, Kang SM: Co-immunization with virus-like particle and DNA vaccines induces protection against respiratory syncytial virus infection and bronchiolitis. Antiviral Res 2014, 110:115-123

27. Hwang HS, Lee YT, Kim KH, Park S, Kwon YM, Lee Y, Ko EJ, Jung YJ, Lee JS, Kim YJ, Lee YN, Kim MC, Cho M, Kang SM: Combined virus-like particle and fusion protein-encoding DNA vaccination of cotton rats induces protection against respiratory syncytial virus without causing vaccine-enhanced disease. Virology 2016, 494:215-224

28. Kim KH, Lee YT, Hwang HS, Kwon YM, Kim MC, Ko EJ, Lee JS, Lee Y, Kang SM: Virus-like particle vaccine containing the F protein of respiratory syncytial virus confers protection without pulmonary disease by modulating specific subsets of dendritic cells and effector T cells. J Virol 2015, 89:11692-11705

29. Go YM, Kim CW, Walker DI, Kang DW, Kumar S, Orr M, Uppal K, Quyyumi AA, Jo H, Jones DP: Disturbed flow induces systemic changes in metabolites in mouse plasma: a metabolomics study using ApoE(-)/(-) mice with partial carotid ligation. Am J Physiol Regul Integr Comp Physiol 2015, 308:R62-R72

30. Hu X, Chandler JD, Orr ML, Hao L, Liu K, Uppal K, Go YM, Jones DP: Selenium supplementation alters hepatic energy and fatty acid metabolism in mice. J Nutr 2018, 148:675-684

31. Yu T, Park Y, Johnson JM, Jones DP: apLCMS: adaptive processing of high-resolution LC/MS data. Bioinformatics 2009, 25:1930-1936

32. Uppal K, Soltow QA, Strobel FH, Pittard WS, Gernert KM, Yu T, Jones DP: xMSanalyzer: automated pipeline for improved feature detection and downstream analysis of large-scale, non-targeted metabolomics data. BMC Bioinformatics 2013, 14:15

33. Li S, Park Y, Duraisingham S, Strobel FH, Khan N, Soltow QA, Jones DP, Pulendran B: Predicting network activity from high throughput metabolomics. PLoS Comput Biol 2013, 9:e1003123

34. Uppal K, Walker DI, Liu K, Li S, Go YM, Jones DP: Computational metabolomics: a framework for the million metabolome. Chem Res Toxicol 2016, 29:1956-1975

35. Uppal K, Ma C, Go YM, Jones DP, Wren J: xMWAS: a data-driven integration and differential network analysis tool. Bioinformatics 2018, 34:701-702

36. Uppal K, Walker DI, Jones DP: xMSannotator: an R package for network-based annotation of high-resolution metabolomics data. Anal Chem 2017, 89:1063-1067

37. Wishart DS, Feunang YD, Marcu A, Guo AC, Liang K, VazquezFresno R, Sajed T, Johnson D, Li C, Karu N, Sayeeda Z, Lo E, Assempour N, Berjanskii M, Singhal S, Arndt D, Liang Y, Badran H, Grant J, Serra-Cayuela A, Liu Y, Mandal R, Neveu V, Pon A, Knox C, Wilson M, Manach C, Scalbert A: HMDB 4.0: the human metabolome database for 2018. Nucleic Acids Res 2018, 46: D608-D617 
38. Wang X, Jones DR, Shaw TI, Cho JH, Wang Y, Tan H, Xie B, Zhou S, Li Y, Peng J: Target-decoy-based false discovery rate estimation for large-scale metabolite identification. J Proteome Res 2018, $17: 2328-2334$

39. Benjamini Y, Hochberg Y: Controlling the false discovery rate: a practical and powerful approach to multiple testing. J R Stat Soc 1995, 57:289-300

40. Garcia F, Ortega A, Domingo JL, Corbella J: Accumulation of metals in autopsy tissues of subjects living in Tarragona County, Spain. J Environ Sci Health A Tox Hazard Subst Environ Eng 2001, 36: $1767-1786$

41. Kollmeier H, Seemann J, Wittig P, Rothe G, Muller KM: Cadmium in human lung tissue. Int Arch Occup Environ Health 1990, 62: 373-377

42. Morton J, Tan E, Suvarna SK: Multi-elemental analysis of human lung samples using inductively coupled plasma mass spectrometry. J Trace Elem Med Biol 2017, 43:63-71

43. Sharma P, Kolawole AO, Core SB, Kajon AE, Excoffon KJ: Sidestream smoke exposure increases the susceptibility of airway epithelia to adenoviral infection. PLoS One 2012, 7:e49930

44. Ciencewicki J, Jaspers I: Air pollution and respiratory viral infection. Inhal Toxicol 2007, 19:1135-1146

45. Hu X, Chandler JD, Park S, Liu K, Fernandes J, Orr M, Smith MR, Ma C, Kang SM, Uppal K, Jones DP, Go YM: Low-dose cadmium disrupts mitochondrial citric acid cycle and lipid metabolism in mouse lung. Free Radic Biol Med 2019, 131:209-217

46. Lee N, Lui GC, Wong KT, Li TC, Tse EC, Chan JY, Yu J, Wong SS, Choi KW, Wong RY, Ngai KL, Hui DS, Chan PK: High morbidity and mortality in adults hospitalized for respiratory syncytial virus infections. Clin Infect Dis 2013, 57:1069-1077

47. Piedimonte G: Respiratory syncytial virus and asthma: speed-dating or long-term relationship? Curr Opin Pediatr 2013, 25:344-349

48. Westerly BD, Peebles RS Jr: Respiratory syncytial virus infections in the adult asthmatic: mechanisms of host susceptibility and viral subversion. Immunol Allergy Clin North Am 2010, 30:523-539. vi-vii

49. Le Y, Zhou Y, Iribarren P, Wang J: Chemokines and chemokine receptors: their manifold roles in homeostasis and disease. Cell Mol Immunol 2004, 1:95-104

50. Miller AL, Bowlin TL, Lukacs NW: Respiratory syncytial virusinduced chemokine production: linking viral replication to chemokine production in vitro and in vivo. J Infect Dis 2004, 189: $1419-1430$

51. Casola A, Burger N, Liu T, Jamaluddin M, Brasier AR, Garofalo RP: Oxidant tone regulates RANTES gene expression in airway epithelial cells infected with respiratory syncytial virus: role in viral-induced interferon regulatory factor activation. J Biol Chem 2001, 276: 19715-19722

52. Culley FJ, Pennycook AM, Tregoning JS, Dodd JS, Walzl G, Wells TN, Hussell T, Openshaw PJ: Role of CCL5 (RANTES) in viral lung disease. J Virol 2006, 80:8151-8157

53. John AE, Berlin AA, Lukacs NW: Respiratory syncytial virusinduced CCL5/RANTES contributes to exacerbation of allergic airway inflammation. Eur J Immunol 2003, 33:1677-1685

54. Hu X, Chandler JD, Fernandes J, Orr ML, Hao L, Uppal K, Neujahr DC, Jones DP, Go YM: Selenium supplementation prevents metabolic and transcriptomic responses to cadmium in mouse lung. Biochim Biophys Acta Gen Subj 2018, 1862:2417-2426

55. Hu X, Fernandes J, Jones DP, Go YM: Cadmium stimulates myofibroblast differentiation and mouse lung fibrosis. Toxicology 2017, 383:50-56

56. Subramanian Vignesh K, Landero Figueroa JA, Porollo A, Divanovic S, Caruso JA, Deepe GS Jr: IL-4 induces metallothionein 3- and SLC30A4-dependent increase in intracellular $\mathrm{Zn}(2+)$ that promotes pathogen persistence in macrophages. Cell Rep 2016, 16: $3232-3246$

57. Ugajin T, Shibama S, Nishida K, Yokozeki H: Metallothioneins are required for human basophil interleukin-4 gene induction via FcvarepsilonRIota stimulation. Allergol Int 2016, 65:466-468

58. Steinke JW, Borish L: Th2 cytokines and asthma: interleukin-4: its role in the pathogenesis of asthma, and targeting it for asthma treatment with interleukin-4 receptor antagonists. Respir Res 2001, 2:66-70

59. Lambert L, Sagfors AM, Openshaw PJ, Culley FJ: Immunity to RSV in early-life. Front Immunol 2014, 5:466

60. Pala P, Bjarnason R, Sigurbergsson F, Metcalfe C, Sigurs N, Openshaw PJ: Enhanced IL-4 responses in children with a history of respiratory syncytial virus bronchiolitis in infancy. Eur Respir J 2002, 20:376-382

61. Boasso A, Vaccari M, Hryniewicz A, Fuchs D, Nacsa J, Cecchinato V, Andersson J, Franchini G, Shearer GM, Chougnet C: Regulatory T-cell markers, indoleamine 2,3-dioxygenase, and virus levels in spleen and gut during progressive simian immunodeficiency virus infection. J Virol 2007, 81:11593-11603

62. Fox JM, Sage LK, Poore S, Johnson S, Tompkins SM, Tripp RA: Drug analog inhibition of indoleamine 2,3-dioxygenase (IDO) activity modifies pattern recognition receptor expression and proinflammatory cytokine responses early during influenza virus infection. J Leukoc Biol 2014, 96:447-452

63. Go YM, Roede JR, Orr M, Liang Y, Jones DP: Integrated redox proteomics and metabolomics of mitochondria to identify mechanisms of cd toxicity. Toxicol Sci 2014, 139:59-73 